\title{
E O VERBO SE FEZ CARNE - QUE SE FEZ OUTRO VERBO: IMAGENS DO CORPO EM MURILO RUBIÃO
}

\author{
Cleber Araújo Cabral - FALE/UFMG
}

\section{INTRODUÇÃO}

\author{
A ficção não é possível sem o real, mas o real \\ também não é possível sem ela. (SCHWAB, G. \\ In: ROCHA, 1999, p. 92) \\ O real é sempre real e imaginário ao mesmo \\ tempo. (LEVY, 2003, p. 28)
}

O que é um corpo? Como o percebemos e como ele pode ser representado na literatura? Quando presente em um texto literário, de que corpo afinal se trata de uma percepção que apenas corresponde a determinações antropomorfizantes ou a outras possibilidades de percepção? Como as imagens literárias do corpo podem propor questionamentos aos modos de representação da experiência? Pode a literatura apresentar questionamentos às percepções e imagens naturalizadas do corpo?

A partir das questões acima, e a fim de elaborar uma reflexão sobre as representações ficcionais do corpo em alguns contos de Murilo Rubião, proponho uma aproximação entre dois movimentos teóricos: primeiro, conjugar as reflexões de Tatiana Levy (LEVY, 2003) acerca da experiência do Fora no pensamento de Blanchot com as reflexões acerca do ser (da) linguagem no pensamento de Foucault. O segundo movimento se dá a partir das especulações de Luis Alberto Brandão acerca das representações do corpo na literatura (BRANDÃO, 2002), tomando como ponto de partida a categoria de sujeito ficcional.

A partir da justaposição das proposições teóricas apresentadas, gostaria de sugerir uma hipótese de leitura a partir de alguns contos de Rubião: é possível que 
um texto literário apresente um modelo de narratividade que atue como uma teoria crítico-especulativa sobre aspectos ontológicos da realidade - aspectos que, de acordo com a provocação contida na epígrafe, são tão reais (e imaginários) quanto a imagens de corpo e mundo presentes na ficção?

A partir do exposto, efetuo o levantamento de algumas representações dos sujeitos ficcionais presentes nas narrativas murilianas, tendo em vista a problematização das noções de real e de imaginário, a partir das imagens do corpo dos sujeitos ficcionais.

\title{
2. REALIDADE E CORPO NA LITERATURA: TENTATIVA DE TEORIZAÇÃO
}

\begin{abstract}
A literatura não é uma explicação do mundo, mas a possibilidade de se vivenciar o outro do mundo. (LEVY, 2003, p. 27)

O imaginário não é uma estranha região situada além do mundo, é o próprio mundo, mas o mundo como um conjunto, como o todo. (BLANCHOT, 1997, p. 305)
\end{abstract}

Quando se entra em contato com a obra de Murilo Rubião, logo chama a atenção a (ir)realidade própria de seus contos. "Cidades imaginárias", geograficamente não localizadas na "vida não-literária" (como "Mangora", “Juparassu”, “a cidade sem nome”, “Pirópolis e a Capital”) ou regiões localizáveis, a partir de referências vagas a lugares reais ("Estrada do Acaba Mundo", "Manacá”, "Nova Lima" ou "um vilarejo de Minas"), deslocamentos temporais ou temporalidades imprecisas - os recuos e os avanços no tempo que acarretam efeitos nas personagens do conto Mariazinha; a cidade que se desloca no tempo e extingue ou cria lugares em Epidólia; o arranha-céu de término imprevisto, cuja construção atravessa os séculos em "O edifício" - e sujeitos ficcionais de contornos e características fugidias, que se apresentam em constante processo de transformação. Como abordar tal obra sem incorrer na tentativa de compará-la com os dados da realidade extratextual e com outros textos literários de aspecto 
naturalista-realista ou documental, que primam pela incorporação verossímil de aspectos do tempo e do espaço sociohistóricos no âmbito da ficção? Como enfatizar a especificidade dos elementos que configuram o mundo ficcional apresentado nas narrativas de Rubião?

Segundo Tatiana Levy (cf. LEVY, 2003, p. 13.), no início do século XX, escritores como Mallarmé, Kafka e Proust anunciavam uma ruptura com algumas das premissas fundamentais de uma determinada concepção de realismo literário. A preocupação realista de dar conta dos mínimos detalhes da realidade foi então substituída pela proposta de enfatizar o ato de criação e a realidade própria da narrativa. Visando a pensar essa nova relação entre literatura e realidade, Blanchot cria o conceito do Fora - compreendido como a potência que a linguagem literária tem de fundar a sua própria realidade, não mais se baseando em referências que lhe sejam exteriores, o que a faria atuar como espelho do mundo, mas referindo-se a si mesma, o que nos leva à necessidade de conceber uma relação outra entre a experiência literária e o real.

O Fora, compreendido como estratégia de pensamento, marca a falência do logos clássico e coloca em xeque noções centrais para a filosofia e para a teoria literária, tais como: autor, linguagem, experiência, realidade e pensamento. Como palavra do Fora, a literatura constitui-se como questionamento dos valores dados, como possibilidade de transgressão. Dessa maneira, estudar a literatura, a partir do conceito do Fora implica em levantar algumas questões:

Quando a idéia de representação enquanto cópia é questionada, como passam a funcionar os elementos constituintes [no caso, as categorias de sujeito, espaço e tempo] do texto literário? E a própria literatura, se não é mais semelhança, se não é mais uma forma de conhecimento do mundo, como pode se dar enquanto experiência? E ainda: de que maneira a experiência literária pode promover um encontro com o pensamento que faz da palavra uma possibilidade de resistência? (LEVY, 2003, p. 14. Grifos meus.)

Tais perguntas interessam como questionamentos a uma concepção de literatura amparada em noções como imitação, verossimilhança, semelhança, repetição do mesmo, concepções que se embasam na correlação propositiva das categorias sujeito, espaço e tempo ('tripé' constitutivo de uma concepção de mundo), ou seja, 
tais questionamentos auxiliam a conceber como imaginamos modelos ontológicos para estabelecer a determinação da natureza de uma narrativa e como propomos outros modelos de funcionamento para essas categorias, a partir do exercício de indeterminação da realidade por meio da ficção.

Desse modo, as determinações da narrativa - as categorias apriorísticas sujeito, espaço, tempo, que atuam como parâmetros de referência e de reconhecibilidade da experiência - se vêem deslocadas em direção ao irreconhecível do ficcional, que seria o mundo "desdobrado em sua outra versão" (LEVY, 2003, p. 27). Tal procedimento ocasiona uma tensão entre as determinações (postuladas por um modelo realista de narrativa) e as possibilidades de indeterminação (advindas das potências do imaginário ${ }^{1}$ e do exercício de modelagem deste a partir do ato ficcional). A partir de tal atrito, vislumbra-se a possibilidade de criação de novas formas de expressão e de pensamento, de outros modelos de narratividade. De acordo com Brandão (2002, p. 183), "De dentro do estatuto narrativo, tensionam-se seus limites. [...] Talvez se possa afirmar que, de dentro da narrativa, a ficção pode propor modelos de narratividade".

Luis Alberto Brandão (2002), em um texto no qual propõe o estudo da categoria corpo em textos da literatura brasileira, parte da análise das categorias (sujeito, espaço, tempo) que atuam como índices norteadores da experiência de leitura, afiançando a legibilidade do literário. O propósito de tal leitura consiste em pensar como esses elementos funcionam como determinações configuradoras da natureza realista da narrativa, que, por sua vez, condicionam a experiência perceptiva do texto. Tomando como base o princípio de semelhança entre texto e

\footnotetext{
${ }^{1}$ Gostaria de esclarecer que proponho uma aproximação do uso do termo "imaginário" feito por Levy (feitas a partir da leitura de Blanchot) com as proposições de Iser (ISER, 1996, p. 209-302) sobre a duplicação da realidade em mundo do como se, efetuada pela ativação do imaginário por meio do ato ficcional. Para compreender a interação (ou o jogo) entre o fictício e o imaginário na elaboração do texto ficcional, utilizo as considerações feitas no capítulo IV de O fictício e o imaginário (ISER, 1996, p. 209-302), ao distinguir o imaginário como ato, faculdade humana e radicalidade institutiva/institucionalizante do ser humano. Sendo assim, compreendo o fictício como um ato intencionado de determinação (como atribuição de sentidos), uma ação de modelagem que ativa o imaginário e lhe atribui um meio de concretização. Já o imaginário não é a produção de imagens, mas um funcionamento indeterminado que viabiliza a elaboração de uma plasticidade própria do humano, que se constitui como possibilidade de uma auto-interpretação do ser humano enquanto homo faber, dado seu caráter difuso, que precisa ser ativado pelo ato ficcional para se concretizar em texto. Dessa maneira, fictício e imaginário são concebidos como categorias em constante interação para a viabilização do texto ficcional, mas que não são determinadas ontologicamente.
} 
realidade extratextual, a partir do qual seria possível reconhecer as ações dos sujeitos ficcionais como sendo passíveis de acontecerem no mundo real, Brandão propõe que

(...) toda narrativa, para ser percebida como tal, pressupõe pelo menos três categorias: tempo, espaço e sujeito. (...) Pode-se falar, assim, que toda narrativa é caracterizada por uma duração, uma localização e uma voz; ou que o movimento narrativo se efetua quando há uma conjugação dos verbos transcorrer, estar e ser. (...) Além disso, também remetem a certas características comumente associadas à noção de corpo, como mobilidade ou mutabilidade, para a categoria tempo; circunscrição ou contextualização, para espaço; e unidade ou identidade, para sujeito. Tais características atuam, no cerne de um texto verbal, como índices de reconhecibilidade dos fundamentos da experiência do corpo. O que equivale a dizer que definem a natureza realista (...) de toda narrativa. (BRANDÃO, 2002, p. 182. Grifos meus.)

Tal formulação estabelece, então, que os parâmetros de legibilidade de uma narrativa ficcional estão pautados pelas relações entre os termos sujeito, espaço e tempo, relações que permitem reconhecer a experiência dos sujeitos do universo literário, como uma experiência humana possível e cognoscível. Esse fato asseguraria, ao texto literário, atuar como forma de conhecimento de mundo, visto que, segundo Brandão, "A narrativa se sustenta (...) no desejo de que a legibilidade se dê via reconhecimento". (BRANDÃO, 2002, p. 183)

A partir do exposto acima, têm-se, então, três categorias delimitadoras dos parâmetros de expressão e representação da experiência: espaço/estar, tempo/transcorrer e sujeito/ser. Três categorias-chave para se pensar (e interrogar) as formas de categorização e a representação dos modos de vida e dos valores que se atribuem às imagens que são modeladas, a partir de referências à experiência humana. Três problemas imbricados por meio dos quais é possível interrogar regimes narrativos e conceber outros modelos de elaboração da fricção entre vida e imaginário, racionalidade e especulação, em busca de possibilidades de abordar e expressar as questões suscitadas por textos ficcionais de contextos históricos específicos.

O que acontece, porém, quando esses elementos-chaves passam a funcionar de outro modo - não mais a partir de uma preocupação em espelhar de maneira verossímil a realidade extratextual que, supostamente, precede a ficção -, mas a 
partir de uma realidade outra, imaginária (própria da narrativa de ficção)? Como essa relação com a linguagem, que se dá a partir da ativação de um imaginário por meio do ato ficcional, viabiliza a criação, em literatura, de uma realidade que se produz, em sua materialidade, como coisa e imagem transgressora da coisa? Que efeitos tal ato ficcional exerce na configuração do que entendemos por sujeito e realidade?

De acordo com Levy, "a realidade da literatura consiste justamente numa realidade imaginária [que seria, ao mesmo tempo, real e imaginária](...) [onde] (...) tudo se torna imagem, ou seja, tudo se desdobra em sua outra versão" (LEVY, 2003, p. 28-27, por ordem de citação). Ainda segundo a autora, “Afirmar que o espaço literário constitui um espaço imaginário significa afirmar que nele tudo é imagem: que a linguagem se desdobra numa linguagem imaginária, o tempo num tempo imaginário e a realidade numa realidade imaginária." (LEVY, 2003, p. 27)

Ao designar o espaço literário como um espaço imaginário - que remete ao espaço de virtualidades que constitui a materialidade da própria linguagem, no qual a realidade, o tempo e os sujeitos manifestam-se como outra coisa, de natureza indeterminada -, Levy nos fornece um elemento importante na compreensão do funcionamento dos elementos constituintes da realidade própria da ficção: tais elementos passam a atuar, então, como experiência de imaginar o mundo, como possibilidade de criar outras imagens que escapam das determinações ontológicas que atribuímos ao que pensamos (e dizemos) ser o mundo, o tempo, o sujeito, o espaço e a linguagem. Ainda segundo a autora, "A literatura não se fixa a nada, nem a um espaço - exterior ou interior -, nem a um tempo, nem a um sujeito. Sua fala é essencialmente errante, móvel, nômade; ela se coloca sempre fora de si mesma." (LEVY, 2003, p. 29)

A partir deste conjunto de proposições teóricas, gostaria de sugerir que consideremos a literatura como uma antropologia especulativa, ficcional, que não apenas oferece uma interpretação das imagens que produzimos de nós, mas, também, viabiliza a possibilidade de elaborarmos críticas a tais interpretações, assim como de reinventarmos nossa leitura de nós mesmos. Assim, ao concebermos a literatura como um medium de reflexão e como experiência de criação de sentidos a partir desta capacidade humana de descodificar imagens, tem-se a possibilidade 
de indagar como são representadas estas experiências do homem e do corpo que percebe (e modela) como se fosse real.

\section{E O PORCO SE FEZ VERBO: CONTORNOS DE SERES E CORPOS HIPOTÉTICOS}

Nesse momento os olhos dos dois se abriram, e eles perceberam que estavam nus. (Gênesis, 3.7)
Através da ficção, o corpo reconhecível é transformado em corpo hipotético. (BRANDÃO, 2002, p. 183)

Desdobrar-se, substituir a intimidade do sujeito pelo Fora da linguagem, eis o projeto moderno da literatura. (LEVY, 2003, p. 29)

A partir da proposição: “(...) o corpo, na literatura, pode ser definido como um 'objeto hipotético"', gostaria de sugerir uma aproximação da obra de Murilo Rubião por meio de um exercício de imaginação crítica. Tal exercício parte da seguinte questão: considerando a natureza indeterminada dos contos de Rubião, como a categoria corpo/sujeito se apresenta problematizada enquanto representação do ser? Gostaria de insinuar uma hipótese interpretativa: por meio da criação de corpos imaginários, de seres de linguagem ${ }^{2}$ que questionem nossa compreensão: acerca do que vemos e dizemos ser o corpo e o humano; de como pensamos que este corpo possa ser; de o que este corpo pode fazer consigo. Em outros termos, como, a partir dos contos de Rubião, colocam-se as questões: o que é o ser/corpo? De que ser/corpo se trata? O que pode o ser/corpo?

Como tal corpo se apresenta como um objeto hipotético, um corpo incerto, contingente, digamos, então, que ele pode se manifestar como quiser - podendo se

\footnotetext{
${ }^{2}$ Faço alusão ao conceito foucaultiano de ser (da) linguagem. Segundo Levy (2003, p. 62-63) "A literatura, na Modernidade, manifesta o reaparecimento do ser vivo da linguagem. (...) A literatura instaura, assim, um espaço de contestação do pensamento representativo. É uma nova ontologia que aqui surge: não mais a do ser-homem, mas a do ser-linguagem. (...) $O$ ser da literatura não concerne nem ao homem nem aos signos, mas ao espaço do duplo. (...) Referindo-se a si própria, a linguagem se constitui como dupla, como dobra."
} 
apresentar tanto como um corpo qualquer, indeterminado a partir de um modelo antropomórfico, ou como 'um corpo qual quer', um corpo que se modela como se quer, que se realiza de acordo com suas necessidades específicas, de modo a criar, para si, um modo singular de estar no mundo.

Se efetuarmos um levantamento das representações do corpo, entendido aqui enquanto uma figura, como uma imagem do pensamento 3 (uma imagem que também é conceito) que viabiliza pensar a natureza impessoal deste corpo próprio ao mundo da ficção, considere-se a possibilidade de tentarmos uma leitura contrastiva, ao tomar tal corpo despersonalizado, corpo impessoal da linguagem, como índice de uma experiência do Fora. Tal corpo seria uma imagem de um regime de narratividade que tensiona a legibilidade pautada no reconhecimento.

Em um breve exame da obra de Murilo Rubião, pode-se perceber e repertoriar algumas imagens de sujeitos ficcionais e de seus corpos singulares como a condição limite do personagem nem morto nem vivo de O pirotécnico Zacarias; o homem de natureza desconhecida que, nascido sem pai ou mãe, deparase consigo pela primeira vez diante de um espelho, já grisalho e entediado, que protagoniza O ex-mágico da Taberna Minhota; o porte, o apetite e o desejo incomensuráveis da protagonista do conto Bárbara; a criatura sem origem ou forma definida, de temperamento instável que pode se transformar em criaturas conhecidas ou desconhecidas em Teleco, o coelhinho; o estranho solitário que se torna transparente com o passar dos dias, afetando corporeamente também o vizinho curioso que o observa em $\mathrm{O}$ homem do boné cinzento; a fecundidade absurda e as crianças inumanas com olhos de vidro em Aglaia; o homem que cansado da humanidade se transforma em porco, verbo e dromedário em Alfredo.

No conto "O pirotécnico Zacarias", somos apresentados a uma situação em que um homem, após ser atropelado na estrada do “Acaba Mundo”, passa a ser tomado como uma situação limite para a compreensão de todos à sua volta. Relutam em aceitá-lo como morto (pois tem "os predicados geralmente atribuídos aos vivos"), em dizer que está vivo (pois dizem que está morto, e que "quem se

\footnotetext{
${ }^{3} \mathrm{O}$ conceito de imagem do pensamento é aqui tomado de empréstimo a Gilles Deleuze. De acordo com o filósofo, a imagem do pensamento seria "a própria imagem do pensamento, a imagem que ele [o pensamento] se dá do que significa pensar, [do que seria] fazer uso do pensamento." (LEVY, 2003, p. 95)
} 
apresenta como ele é outro'), ou em dizer que se tornou outra coisa, pois não compreendem sua condição-limite - que impede o protagonista de construir um entendimento sobre a própria condição. Seguem-se alguns exemplos:

Para tornar mais confusa a situação, sentiam a impossibilidade de dar rumo a um defunto que não perdera nenhum dos predicados geralmente atribuídos aos vivos. (RUBIÃO, 2006, p. 16)

Não fosse o ceticismo dos homens, recusando-se aceitar-me vivo ou morto, eu poderia abrigar a ambição de construir uma nova existência. (RUBIÃO, 2006, p. 17)

Só um pensamento me oprime: que acontecimentos o destino reservará a um morto se os vivos respiram uma vida agonizante? (RUBIÃO, 2006, p. 18)

Em “O ex-mágico da Taberna Minhota”, deparamo-nos com um (in)certo personagem que tem, como maior incômodo, ter se deparado um dia frente a um espelho, já de cabelos grisalhos. "Fui atirado à vida sem pais, infância ou juventude. (...) Nascera cansado e entediado” (RUBIÃO, 1998, p. 07). Sua 'condição de mágico' se apresenta, para ele, tão naturalmente desconhecida e incômoda como o fato de existir sem ter nascido, e de ser capaz de criar outros seres, mas incapaz de dar um fim a sua própria existência: "Rolei até o chão, soluçando. Eu, que podia criar outros seres criar outros seres, não encontrava meios de libertar-me da existência" (RUBIÃO, 1998, p. 07).

Por que me emocionar, se não me causavam pena aqueles rostos inocentes, destinados a passar pelos sofrimentos que acompanham o amadurecimento do homem? Muito menos me ocorria odiá-las por terem tudo que ambicionei e não tive: um nascimento e um passado. (RUBIÃO, 1998, p. 08-09)

Se, distraído, abria as mãos, delas escorregavam esquisitos objetos. A ponto de me surpreender, certa vez, puxando da manga da camisa uma figura, depois outra. Por fim, estava rodeado de figuras estranhas, sem saber que destino lhes dar. (RUBIÃO, 1998, p. 09)

Numa dessas vezes, irritado, disposto a nunca mais fazer mágicas, mutilei as mãos. Não adiantou. Ao primeiro movimento que fiz, elas reapareceram novas e perfeitas nas pontas dos tocos de braço. Acontecimento de desesperar qualquer pessoa, principalmente um mágico enfastiado do ofício. (RUBIÃO, 1998, p. 10) 
“Teleco, o coelhinho" nos apresenta uma criatura (a princípio um coelho) que fala e que transforma-se em outros animais (sempre de acordo com sua vontade, que é condicionada pelo interesse em agradar ou desagradar a alguém), conhecidos ou desconhecidos. Certo dia, ele decide ser 'apenas homem'. Ao fim do conto, quando Teleco morre, fica a questão: teria sido humano, em algum momento, antes de se tornar um polimorfo?! Ou 'teria corrompido' sua potência metamórfica (seus devires) ao tentar tornar-se humano?

Diante de mim estava um coelhinho cinzento(...). (...) convidei-o a residir comigo.

- À noite - prosseguiu - serei cobra ou pombo. Não lhe importará a companhia de alguém tão instável?

Respondi-lhe que não e fomos morar juntos. (RUBIÃO, 1998, p. 144)

Amava as cores e muitas vezes surgia transmudado em ave que as possuía todas e de espécie inteiramente desconhecida ou de raça já extinta.

- Não existe pássaro assim!

- Sei. Mas seria insípido disfarçar-me somente em animais conhecidos. (RUBIÃO, 1998: 146)

- De hoje em diante serei apenas homem.

- Homem? - indaguei atônito. (...)

- Vamos, Teleco, chega de trapaça.

(...) - Teleco?! Meu nome é Barbosa (...). (RUBIÃO, 1998, p. 147-148)

- Voltar a ser coelho? Nunca fui bicho. Nem sei de quem você fala.

- Falo de um coelhinho cinzento e meigo, que costumava se transformar em outros animais. (RUBIÃO, 1998, p. 149)

Ao acordar, percebi que uma coisa se transformara nos meus braços. No meu colo estava uma criança encardida, sem dentes. Morta. (RUBIÃO, 1998, p. 152)

No conto "Alfredo", um homem, incomodado com a vida entre seus semelhantes, opta por tornar-se outra coisa que não humano. Mas, o que pode um corpo, literário ou não? Pode tornar-se porco? Sim, entre outras formas. Ainda é possível explorar as potências e devires do humano por meio da linguagem, mesmo que, para repensar o humano, seja preciso deformá-lo, inumanizá-lo. A partir de tal procedimento, no qual o familiar passa ao desconhecido, de comum se configura como estranho, coloca-se em questão o estatuto convencionado do corpo. 
De início, Alfredo pensou que a solução seria transformar-se num porco, convencido da impossibilidade de conviver com seus semelhantes, a se entredevorarem no ódio. (RUBIÃO, 1998, p. 69)

Imaginou, então, que fundir-se numa nuvem é que resolvia. Resolvia o quê? Tinha que resolver algo. Foi nesse instante que lhe ocorreu transmudar-se no verbo resolver.

E o porco se fez verbo. (...) (RUBIÃO, 1998, p. 69)

Entretanto, o verbo resolver é, obviamente, a solução dos problemas, o remédio dos males. Nessa condição, não teve descanso, resolvendo assuntos, deixando de solucionar a maioria deles. (...) E transformou-se em dromedário, esperando que beber água o resto da vida seria um ofício menos extenuante. (RUBIÃO, 1998, p. 69)

\section{MUNDOS IRREAIS, CORPOS IMAGINÁRIOS, SERES DE LINGUAGEM}

O espaço literário é, portanto, um espaço original, onde as coisas e os seres não são ainda. A literatura revela os seres em sua indeterminação original, antes que eles sejam de fato. (LEVY, 2003, p. 33)

O corpo também é conceito. O sensível também é da ordem do inteligível. (BRANDÃO, 2002, p. 182)

Posso dizer que, se houve um propósito com este texto, ele pode ser expresso da seguinte maneira: como é possível, a partir de um texto como o de Murilo Rubião, no qual a (ir)realidade imaginária se impõe como espaço de indeterminação, viabilizar um exercício de leitura em que a imagem dos sujeitos ficcionais possa auxiliar como um parâmetro de compreensão da singular realidade própria da narrativa e da linguagem ficcional? Se o corpo (como sugere a epígrafe) também é da ordem do conceito, portanto da invenção e da fabulação, podemos dizer que ele é da ordem do imaginário - tal como a realidade a qual pertence que, antes de ser inteligível, antes de 'ser vista e tornada dizível e compreensível', coocorre com o momento de sua elaboração, sendo objeto e imagem (ou o corpo e a outra versão do corpo) simultaneamente. 
Ao relacionar os conceitos de experiência do Fora, ser (da) linguagem, e sujeitos ficcionais na compreensão do funcionamento dos elementos constituintes do texto ficcional, tentei apresentar uma abordagem conceitual que, partindo das possibilidades abertas por Blanchot e Foucault, instigasse a

(...) interrogar em que medida a literatura constitui um arranjo específico no qual a inevitável ordenação da linguagem verbal (o irrecusável poder "estriador" do espaço literário) pode ser constantemente reinventada com efeitos mais ou menos eficazes em determinado contexto de leitura - pela suspensão dos códigos ordenadores (pela propensão "alisadora" do espaço literário). (BRANDÃO, 2007, p. 215)

Dito isso, cabe perguntar: quais imagens de sujeito, espaço e tempo ficcionais a obra apresenta e problematiza? Que parâmetros ordenadores da linguagem (e da experiência) o texto suspende? Ao questionar os parâmetros de regimes narrativos vigentes à sua época, a ficção de Rubião propõe modelos de espacialidade e possíveis regimes de temporalidade e corporeidade que atuam na configuração de um imaginário que, a partir da indeterminação dessas categorias (que se impõe como se fosse cotidiana), produz a emergência de uma irrealidade ficcional que questiona a validade de um modelo realista-verossímil - mas que não postula em seu lugar outra concepção de realismo literário.

Se o espaço literário se apresenta como usina produtora de plasticidades que viabilizam elaborarmos (e questionarmos) a nós mesmos, essa zona de indiscernibilidade - magma que torna possível ao pensamento pensar, de onde as potências do imaginário se enunciam para as possibilidades de expressão da linguagem - se constitui não só como um meio de reflexão, mas também como “(...) uma experiência que, ilusória ou não, aparece como meio de descoberta e de um esforço, não para expressar o que sabemos, mas para sentir o que não sabemos." (BLANCHOT, 1997, p. 81). 


\section{REFERÊNCIAS}

BLANCHOT, Maurice. A parte do Fogo. Rio de Janeiro: Rocco, 1997.

BRANDÃO, Luis Alberto. Teoria do corpo na literatura brasileira contemporânea. In: DUARTE, R.; FIGUEIREDO, V.; FREITAS, V.; KANGUSSU, I. (orgs.). Kathársis: reflexos de um conceito estético. Belo Horizonte: C/Arte, 2002. P. 182-187.

BRANDÃO, Luis Alberto. Linhas do imaginário. In: Grafias da identidade: literatura contemporânea e imaginário nacional. Rio de Janeiro / Belo Horizonte: Lamparina editora / Fale (UFMG), 2005.

BRANDÃO, Luis Alberto. Espaços literários e suas expansões. ALETRIA. Revista de estudos de literatura. v. 15, Caderno Temático "Poéticas do espaço", Belo Horizonte, jan./jun. 2007. P. 207-219.

COUY, Venus Brasileira. Contornos do corpo. Revista Travessias. Vol. 3, n. 1, 2009. Disponível em: http://www.unioeste.br/prppg/mestrados/letras/revistas/travessias/ed_005/artigos/ ARTE\%20E\%20COMUNICA\%C7\%C3O/pdfs/CONTORNOS\%20DO\%20CORPO.pdf. Acesso em: 20 abr. 2010.

ISER, Wolfgang. O fictício e o imaginário - Perspectivas de uma Antropologia Literária. Trad. Johannes Kretschmer. Rio de Janeiro: EdUERJ, 1996.

LEVY, Tatiana Salem. A experiência do fora: Blanchot, Foucault e Deleuze. Rio de Janeiro: Relume Dumará, 2003.

ROCHA, João Cezar de Castro (org.). Teoria da ficção - indagações à obra de Wolfgang Iser. Rio de Janeiro: EDUERJ, 1999.

RUBIÃO, Murilo. Contos reunidos. Posfácio de Vera Lúcia Andrade. São Paulo: Editora Ática, 1998. 